\title{
A RIQUEZA SOCIOEMOCIONAL E O DECLÍNIO EM UMA EMPRESA FAMILIAR: UM ESTUDO DA GUERRA S.A.
}

\author{
Socioemotional wealth and decline in a family-owned firm: A study of \\ the Guerra S.A.
}

Michele Josiane Rutz Buchweitz

E-mail: michelejrb@gmail.com

Mestraem ContabilidadepelaUniversidadeFederaldoRioGrande;Especialistaem ControladoriaeFinançaspela

Fatec - Serviço Nacional de Aprendizagem Comercial (Senac).

Endereço para contato:

Avenida Itália, km 8, 96203-900, Carreiros,

Rio Grande, Rio Grande do Sul, Brasil.

https://orcid.org/0000-0002-5523-9882

Ana Paula Capuano da Cruz

E-mail: anapaulacapuanocruz@hotmail.com

Doutora em Controladoria e Contabilidade pela Universidade de São Paulo; Mestra em Contabilidade pela Universidade FederaldoParaná;Professora Adjuntanolnstitutode Ciências Econômicas, Administrativase Contábeis da Universidade Federal do Rio Grande.

https://orcid.org/0000-0002-6064-1614

Marco Aurélio Gomes Barbosa

E-mail: marcoaureliogb@gmail.com

Doutor em Ciências Contábeis pela Universidade do Vale do Rio dos Sinos; Mestre em Ciências Contábeise

Controladoria pelaUniversidadedoValedoRiodosSinos;ProfessornoCursodeCiênciasContábeisenoPrograma de Pós-graduação em Contabilidade da Universidade Federal do Rio Grande.

https://orcid.org/0000-0002-5574-4168

Thais Aparecida Pereira

E-mail: thais.2013.rs@gmail.com

Mestra em Contabilidade pela Universidade Federal do Rio Grande; Bacharela em Administração pela Universidade Federal do Rio Grande; Mestranda em Contabilidade no Instituto de Ciências Econômicas, Administrativas e Contábeis da Universidade Federal do Rio Grande. https://orcid.org/0000-0001-5855-9403

Artigo recebido em 27 de agosto de 2018. Aceito em 5 de junho de 2019. 


\section{Resumo}

Este estudo buscou analisar os fatores que levaram a empresa Guerra S.A. ao declínio e posterior encerramento das atividades. A informação fidedigna proporcionada pela contabilidade permite decisões assertivas ao longo da vida das organizações, tornandoas competitivas e propiciando desenvolvimento no decorrer das gerações familiares donas do negócio. Assim, desenvolveu-se esta pesquisa sob a perspectiva dos ciclos evolutivos e da riqueza socioemocional, abordando-se, em especial, o declínio organizacional-uma fase do modelo do ciclo de vida proposto por Miller e Friesen (1984). A investigação foi realizada por meio de análise de conteúdo de reportagens extraídas de jornais e outras mídias virtuais. Optou-se por uma abordagem qualitativa, ao utilizar dados obtidos de fonte escrita. As comprovações obtidas sugerem que o declínio, última fase do ciclo de vida organizacional e, consequentemente, a falência e o encerramento das atividades da Guerra S.A. deveram-se muito pelo fato de os tomadores de decisão não atuarem de forma eficaz e enérgica na resolução dos problemas enfrentados pela empresa e por disputas de interesse entre a controladora e o membro familiar que respondia por cotas minoritárias das ações. Em síntese, esta pesquisa contribui para que empresas familiares e seus representantes compreendam a relevância que aspectos emocionais podem trazer à empresa familiar por meio da abordagem da riqueza socioemocional.

Palavras-chave: Declínio organizacional. Empresa familiar. Riqueza socioemocional.

\section{Abstract}

This study sought to identify the factors that led the company Guerra S.A. to the decline and subsequent closure of the activities. Accurate information provided by accounting enables assertive decisions over the life of organizations, making them competitive and fostering development over the generations of family business owners. Thus, this research was developed from the perspective of evolutionary cycles and social-emotional richness, focusing in particular on organizational decline-a phase of the life cycle model proposed by Miller and Friesen (1984). The research was carried out through content analysis of articles extracted from newspapers and other virtual media. We opted for a qualitative approach, when using data obtained from written sources. The evidence obtained suggests that the decline, the last phase of the organizational life cycle and, consequently, the bankruptcy and closure of the activities of Guerra S.A. was due to the fact that decision-makers do not act effectively and energetically in solving problems faced by the company and by disputes of interest between the parent company and the family member that was responsible for minority shares. In summary, this research helps family companies and their representatives understand the relevance that emotional aspects can bring to the family business through the socio-emotional richness approach.

Keywords: Organizational decline. Family business. Socioemotional wealth.

\section{INTRODUÇÃO}

Ao ser empregada oportunamente, a informação contábil diminui as incertezas que preocupam seus usuários e a assimetria informacional de forma geral (Jupetipe, 2017). Segundo a autora, divergências nas informações disponibilizadas pela contabilidade geram, inclusive, problemas nos procedimentos de falência, assim como em casos de recuperação judicial. 
Na ótica da Ciência da Informação, as informações contábeis representam documentos com dupla função, conforme Valente (2014): "a) legal, comprobatória de atividades desenvolvidas pela instituição produtora; e b) informativa, de interesse para potenciais usuários que atuam no mercado de capitais" (p. 263). Para Ribeiro, Lopes e Pederneiras (2009) há uma ampla variedade de usuários que se utilizam das informações contábeis disponibilizadas pelas empresas, e, por isso, privilegia-se o usuário externo em detrimento da própria empresa, em busca da uniformidade das demonstrações exigidas.

Tanto para cumprir a legislação quanto para atrair novos investidores, as empresas exploram diferentes meios de comunicação como um recurso para expor ou ocultar informações que não têm interesse de que se tornem, ou não, públicas, bem como para desviar a atenção ou até mesmo para acobertar possíveis ilícitos. Assim, nem toda informação é divulgada no intuito de revelar o que realmente está acontecendo com a empresa, nem sempre o que está disponível na mídia é a integralidade dos fatos que ocorreram em determinada circunstância, como o que pode ser observado em questões omitidas pelas empresas em seus demonstrativos e balanços, por exemplo.

Ao longo da vida das empresas, estas sofrem com influências, internas ou externas. Distintivamente a outros modelos de organização, as empresas familiares possuem aderência a um conjunto de interferências da própria família no contexto empresarial, que podem ser compreendidas a partir de abordagens comportamentais analisadas à luz de abordagens teóricas, como a evidenciada na Socioemotional Wealth (SEW) ou Riqueza Socioemocional, esta que vem sendo utilizada no estudo desse tipo de organização.

Entre os mais variados tipos de organizações, destacam-se as empresas familiares, bastante representativas no cenário brasileiro (Price Waterhouse e Coopers [PWC], 2016). Assim, quando se trata de empresas controladas por famílias, a compreensão do declínio e dos comportamentos e decisões tomadas pela empresa/família pode apresentar um componente adicional: a influência exercida pelos membros familiares. Segundo Frezatti, Bido, Mucci, e Beck (2017), tal influência adiciona complexidade aos modelos de ciclo de vida organizacional no caso de empresas familiares, em razão das peculiaridades apresentadas por esse tipo de organização.

Além disso, as empresas passam por diversos processos ao longo de sua vida, atravessando dificuldades impostas por informações desencontradas e que tornam o ambiente organizacional propício a desencadear ciclos evolutivos nem sempre positivos à organização. Considerando-se essa perspectiva, as atividades empresariais podem ser exploradas a partir do seu ciclo de vida, tentando-se compreender a evolução das organizações (Frezatti et al., 2017). As empresas nascem, crescem e, apesar do desejo dos proprietários de manutenção das atividades de longo prazo, algumas acabam entrando em uma fase denominada declínio. 
Estudos envolvendo estágios de ciclo de vida baseiam-se na concepção de que as empresas experimentam os estágios no decorrer de suas vidas, em que, conforme Necyk e Frezatti (2010), "cada estágio está associado a padrões ambientais, estratégicos, estruturais e de tomada de decisão característicos" (p. 726). Conforme Serra, Pinto, Guerrazzi, e Ferreira (2017) as pesquisas realizadas no ciclo de vida de declínio são escassas e um dos pontoschave para essa carência é de que, segundo Serra et al., "o declínio organizacional está relacionado à deterioração da base de recursos e ao desempenho de uma organização por um período de tempo sustentado. Embora alguns estudos tenham sido conduzidos, continua sendo um fenômeno pouco estudado, apesar da sua importância" (p. 2). Os autores reforçam que existem ao menos três aspectos distintos que podem ser percebidos nessa fase da vida organizacional, quais sejam: declínio organizacional em si; estudos sobre a reviravolta; e mortalidade. Nesse contexto, destaca-se a necessidade de uma melhor definição da fase de declínio, questões cognitivas e outros aspectos sobre a tomada de decisões e problemas metodológicos específicos, a fim de entender melhor por que as empresas entram nessa fase, como evitá-la, identificando de que maneira a capacidade e os processos decisórios acontecem, culminando em perda de valor e deterioração dos recursos. Ainda, é preciso avaliar se as teorias que explicam o crescimento também são capazes de explicar o declínio (Serra et al.).

Entre os mais variados tipos de organizações, destacam-se as empresas familiares, bastante representativas no cenário brasileiro (PWC, 2016). Assim, quando se tratam de empresas controladas por famílias, a compreensão do declínio e dos comportamentos e decisões tomadas pela empresa/família podem apresentar um componente adicional: a influência exercida pelos membros familiares. Segundo Frezatti et al. (2017), tal influência adiciona complexidade aos modelos de ciclo de vida organizacional no caso de empresas familiares, em razão das peculiaridades apresentadas por esse tipo de organização.

Estudos envolvendo estágios de ciclo de vida baseiam-se na concepção de que as empresas experimentam os estágios no decorrer de suas vidas, em que, para Necyk e Frezatti (2010), "cada estágio está associado a padrões ambientais, estratégicos, estruturais e de tomada de decisão característicos" (p. 726). Neste estudo buscou-se explorar associadamente o ciclo de vida (mais especificamente o estágio de declínio), uma empresa familiar e a riqueza socioemocional no âmbito organizacional.

Diante do exposto, esta pesquisa explora o declínio a partir da situação da Guerra S.A. - uma empresa familiar sediada no Rio Grande do Sul, a qual iniciou suas atividades em 1970 - que experimentou fases de crescimento e maturidade e, em novembro de 2017, teve sua falência decretada pela justiça. Assim, desenvolve-se esta investigação a partir da seguinte questão de pesquisa: como ocorreu o declínio da empresa Guerra S.A.?

Dessa maneira, busca-se analisar os fatores que levaram uma das maiores fabricantes de implementos rodoviários da América Latina ao enfrentamento da fase de declínio, e 
quais peculiaridades podem ser visualizadas nessa fase. Mapear os principais fatores que contribuíram para o declínio organizacional de uma empresa como a Guerra S.A. é relevante porque contribui para outras organizações que se encontram no estágio de declínio do ciclo de vida, buscando informações sobre as circunstâncias que levaram a empresa a chegar à fase vivenciada. De forma complementar, espera-se contribuir para o debate acadêmico, por meio de reflexões para futuros estudos sobre os constructos apresentados em conjunto neste estudo: ciclo de vida (declínio), empresa familiar e riqueza socioemocional.

A principal contribuição deste estudo repousa no sentido de descrever especificidades de uma fase da vida das organizações pouco estudada: o declínio. Busca elucidar questões para a melhor compreensão de como a interferência emocional nas decisões em uma empresa familiar pode afetar o conjunto organizacional como um todo. E, ainda, pretende enaltecer que as peculiaridades de organizações familiares, como riqueza socioemocional, devem ser levadas em conta, com maior atenção quando ela se encontra em transição para a profissionalização, esta definida por Giovannoni, Maraghini, e Riccaboni (2011) como um processo em que gerentes profissionais se tornam parte do negócio da família, tanto em nível gerencial quanto em nível de propriedade. O declínio é explorado nessa investigação a partir do modelo de ciclo de vida de Miller e Friesen (1984), buscando-se impulsionar o debate sobre os constructos analisados.

\section{QUADRO TEÓRICO DE REFERÊNCIA}

O quadro teórico que serve de referência para o desenvolvimento desta pesquisa leva em conta especificidades das empresas familiares; o ciclo de vida que a organização enfrenta, com destaque para o estágio de declínio; e, por fim, a riqueza socioemocional que fornece o aporte teórico para a discussão.

\subsection{EMPRESA FAMILIAR E O DECLÍNIO ORGANIZACIONAL}

Para Leone (2004), a empresa familiar pode ser conceituada a partir de três abordagens, as quais são: propriedade, em que o controle é usufruído pela família proprietária da empresa (a qual possui seu controle ou a maior parte de seu capital); gestão, os membros da família ocupam altos cargos na empresa; e sucessão, os membros da família ocupam os cargos vagos por seus parentes continuamente. Na presente pesquisa, a perspectiva utilizada para abordar o estudo da Guerra S.A. é a de propriedade, visto que a empresa possuía como elemento de associação à empresa familiar o fato de deter o controle do negócio. Silva e Muniz (2003) desenvolveram um estudo que mescla o tema sobre empresa 
familiar, o processo sucessório, as relações de poder, a profissionalização e a sobrevivência desse tipo de organização. A análise da fase em que a empresa vivenciava e a venda do empreendimento familiar para uma empresa transnacional também foram abordadas. Os autores retratam a ascensão, o declínio e a falência de uma empresa com gestão familiar com 73 anos de existência. A falência é analisada no presente artigo, o qual busca entender quais fatores levaram ao declínio da empresa objeto deste estudo.

A representatividade e a importância da empresa familiar na economia mundial são enaltecidas por Silva e Muniz (2003). Para os autores, da junção de família e empresa surge a empresa familiar, a qual quando sobrevive aos ciclos de vida, perpassa pela sucessão. $A$ sobrevivência da empresa nas mãos da família, muitas vezes, depende do desempenho do sucessor na condução do empreendimento (Silva \& Muniz, 2003). Quanto à sobrevivência das empresas familiares, existe uma proporcionalidade entre o surgimento, as extinções e os fechamentos desse tipo de organização. Outro fator relevante é a maneira com que essas empresas são estudadas, a partir das mudanças que ocorrem na própria família, assim, muitos acontecimentos que se desenrolam no âmbito familiar são também sentidos na vida profissional da organização familiar (Silva \& Muniz, 2003).

Um dos achados da pesquisa de Silva e Muniz (2003) diz respeito à fragilidade do empreendimento familiar quando os laços de confiança na família proprietária são desfeitos, acarretando problemas na continuidade do negócio. Conforme os autores recém-referidos, os conflitos resultantes dessa quebra de confiança ocasionaram a venda total da empresa que até então se baseava na família. Assim, o estudo permite analisar aspectos que podem estar igualmente vinculados na empresa familiar objeto desta pesquisa sobre a Guerra S.A. Três (2010) objetivou identificar as principais causas de declínio empresarial em uma empresa familiar e as ações que promovem o turnaround dos negócios nos diferentes estágios do ciclo de vida organizacional. Um dos principais achados da pesquisa foi que as crises econômicas retratam as vulnerabilidades das empresas, entretanto, o autor cita o declínio como uma fase antecedente às crises, justificando a necessidade de se promoverem a identificação e o controle desse estágio.

Para Três (2010) o declínio e a retomada do desempenho anteriormente apresentados pela empresa são considerados processos que englobam dimensões econômicas, financeiras, estratégicas e humanas. Todas essas inter-relações sofrem influências externas e internas, e contribuem para a modificação do ambiente empresarial. Uma empresa mal-gerida e que sofre com fatores externos (regulações, concorrência, inflação e juros elevados) naturalmente tende a enfrentar problemas de ordem financeira na fase de declínio organizacional, aumentando ainda mais as dificuldades nesse estágio do ciclo de vida (Três, 2010).

As empresas, no geral, desenvolvem suas atividades e passam por diferentes fases. Seguindo essa linha de raciocínio, alguns modelos foram desenvolvidos como forma de enquadrar as principais características de cada uma dessas fases, também denominadas 
estágios. Entre os modelos propostos na literatura, o de Miller e Friesen (1984) se sobressai em relação a outros, por sua profundidade conceitual e testes empíricos (Necyk \& Frezatti, 2010). Segundo esses autores, o ciclo de vida das organizações pode ser segregado em cinco estágios distintos: nascimento-a empresa busca tornar seu negócio viável, geralmente é gerenciada pelos próprios donos, tem processos simples e informais; crescimento-nesta fase a empresa já estaria estabelecida e usufruindo dos efeitos positivos de seu produto no mercado, já existe algum nível de delegação de autoridade e os processos são formalizados; maturidade-os níveis de vendas se estabilizam, não são mais produtos inovadores e a organização se torna mais burocrática; renascimento-as estruturas são departamentalizadas e complexas, com sistemas de controle e planejamento mais sofisticados; e declínio-a empresa estagna, não há mais inovação e a rentabilidade diminui.

As características retratadas por Miller e Friesen (1984) sobre o ciclo de vida, mais especificamente o declínio, são apresentadas na Figura 1.
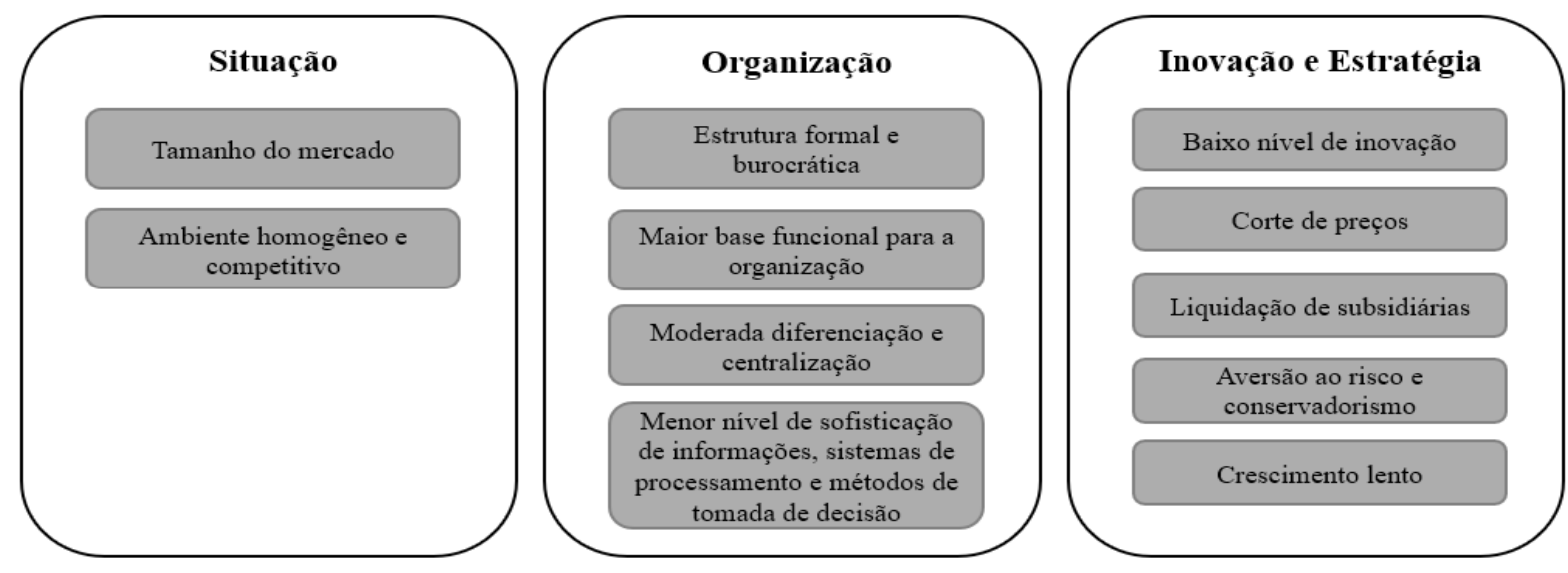

Figura 1. Características da fase de declínio no ciclo de vida organizacional. Adaptada de "A longitudinal study of the corporate life cycle." por D. Miller, \& P. Friesen, 1984, Management Science, 30(10), pp. 1161-1183.

O declínio é o estágio analisado nesta pesquisa, por esse motivo, convém aprofundar sua análise e explanação. No declínio, as empresas se tornam estáticas, focalizadas no setor interno e quase não há sistemas de controle internos ou externos. As áreas e hierarquias sofrem com a falta de comunicação e as decisões são marcadas por altos níveis de conservadorismo e centralização. A organização produz soluções pouco relevantes, face ao profundo grau de problematização enfrentado (Santos \& Barbosa, 2011; Necyk \& Frezatti, 2010).

A partir da descrição das fases do ciclo de vida das organizações, Miller e Friesen (1984) fazem referência às mudanças que podem desencadear um novo arranjo na empresa em decorrência das fases percorridas. Esses eventos/hipóteses dizem respeito à/ao: estrutura, tarefas mais difíceis e estruturas mais sofisticadas, com procedimentos de processamento de dados e controles formais, o que tende a ser reduzido na fase de declínio; estilo de tomada de decisão, com exceção da última fase (declínio), na qual existe uma complexidade alta 
com relação à tomada de decisões; situação organizacional, em que as empresas tendem a ter um grande crescimento nas primeiras quatro fases (com exceção do declínio), com diminuição da centralização da propriedade; e estratégia, visto que nas fases de nascimento, crescimento e maturidade há predominância de renovação das estratégias e inovação, já nas demais fases, o movimento é inverso.

\subsection{RIQUEZA SOCIOEMOCIONAL E EMPRESA FAMILIAR}

Para a compreensão de alguns aspectos da configuração das empresas familiares, existe um arcabouço teórico específico. A riqueza socioemocional surgiu como uma evolução da teoria da agência, incorporando a abordagem comportamental baseada no conflito advindo de uma nova configuração das empresas, que até então lidavam apenas com os interesses do dono do negócio, o qual agora passa a ser gerenciado, também, por pessoas externas à organização, com interesses próprios, que nem sempre compactuam com os ideais do proprietário (Gomez-Mejia, Cruz, \& Imperatore, 2014). A abordagem da riqueza socioemocional propicia comportamentos colaborativos, mas também atenta ao oportunismo e egoísmo, assim como visualizado na teoria da agência (Prencipe, Bar-Yosef, \& Dekker, 2014). A riqueza socioemocional, para Stankiewicz (2016), envolve aspectos emocionais em vez de atribuir importância financeira de forma exclusiva, conservando o controle da família sobre o negócio, os vínculos familiares criados dentro da organização, o apego emocional desenvolvido na empresa e a atuação dos membros familiares, descritos a seguir nas dimensões da riqueza socioemocional (SEW).

A SEW é dividida em cinco dimensões: controle e influência familiar no negócio, decorrentes do acompanhamento do dia a dia da organização por parte da família; identificação dos membros da família com a empresa, havendo uma fusão entre o que a família e a empresa representam, transformando as duas personagens em uma só; vínculos sociais, por meio do compartilhamento dos valores familiares instituídos na organização; apego emocional da família, no comparativo com as empresas não familiares esse aspecto está fortemente associado às dificuldades enfrentadas para atingir o que foi alcançado pelos membros da família na organização; e renovação dos laços familiares por meio da sucessão (Berrone, Cruz, \& Gomez-Mejia, 2012; Stankiewicz, 2016).

Empiricamente, a abordagem da riqueza socioemocional tem ganhado a atenção de inúmeros pesquisadores, possibilitando a operacionalização dos constructos recém-discutidos em diversas empresas familiares. Nesse sentido, destaca-se o estudo de Sanchez-Famoso, Maseda, e Iturralde (2013), que analisaram a influência do capital social dos membros da família sobre o capital social de membros que não são da família em 172 empresas familiares da Espanha. Os autores observaram que o capital social familiar influencia direta 
e positivamente o capital social não familiar e as relações entre algumas das dimensões do capital social em cada grupo, e forneceram subsídios para afirmar que as relações entre os membros da família são fundamentais para o aumento do capital social não familiar. Os achados indicam que o comportamento e as relações instituídas entre os membros da família e aqueles que não são da família sofrem influência direta e concomitante.

Kalm e Gomez-Mejia (2016) revisaram a literatura existente sobre riqueza socioemocional. Os autores defendem a ideia de que a necessidade das empresas familiares de preservação de riqueza socioemocional explica as diferenças comportamentais entre empresas familiares e não familiares na tomada de decisões gerenciais. Martínez-Romero e Rojo-Ramírez (2016) exploraram as definições sobre a riqueza socioemocional em pesquisas anteriores e construíram uma conceituação própria. Trataram ainda sobre três questões tidas como controversas na abordagem, que são: a relação entre SEW e valor emocional; as situações que poderiam levar a diferentes níveis de SEW; e os efeitos de propriedade e gerenciamento na SEW de uma empresa familiar. Segundo Martínez-Romero e Rojo-Ramírez, a SEW tem implicações e consequências importantes para as empresas familiares, e, por isso, é considerada como o paradigma mais importante nesse campo de estudo (Berrone et al., 2012).

Stankiewicz (2016) utilizou a abordagem da riqueza socioemocional com a intenção de retratar as metas não financeiras e a possível negligência ao desempenho financeiro que as empresas familiares apresentam quando comparadas a partir das metas da SEW estabelecidas pela família. Entre as implicações destacadas pelo autor, a principal foi relacionada a associações negativas da SEW com o desempenho financeiro, o que acabou não sendo confirmado nas empresas familiares, ao menos no que diz respeito a duas (identificação e controle transgeracional) das cinco dimensões do modelo SEW analisadas pelo autor. Um dos achados da pesquisa foi de que tanto a SEW quanto as dimensões da identificação e controle transgeracional tiveram uma leve associação positiva no desempenho financeiro das empresas familiares.

Mucci (2018) utilizou a SEW para avaliar as intenções com relação ao valor de afeto que a família controladora confere à empresa. O autor empregou duas das cinco dimensões da SEW: controle e influência familiar; renovação dos laços familiares, demonstrando que as diferentes intenções da SEW impõem distintas influências, em cada subdimensão, analisadas no âmbito da governança da empresa familiar. Abordando a escassez de estudos que tratam sobre as especificidades da família e sobre o desenho dos controles gerenciais, o autor ampliou a pesquisa no campo ao recorrer à visão da riqueza socioemocional para compreender a disposição da família controladora do negócio. Mucci indica que existe uma associação significativa entre o envolvimento da família controladora na propriedade e as dimensões de disposição familiar na empresa. Por fim, destaca-se que, além de se levarem em conta aspectos ligados às emoções na gestão da empresa, também é preciso se atentar aos 
valores familiares, que podem perpetuar a organização (Helsen, Lybaert, Steijvers, Orens, \& Dekker, 2017). Os autores atribuem à SEW alguns impactos na tomada de decisão no que diz respeito ao comportamento altruísta evidenciado entre os proprietários. Quando a empresa familiar passa por um processo de profissionalização, a riqueza socioemocional tende ao enfraquecimento ou desaparecimento, percebidos com a saída dos membros familiares da estrutura gerencial da empresa. Nesse sentido, Miller e Breton-Miller (2014) asseguram que os estudiosos da SEW são coerentes ao afirmar que as empresas familiares são motivadas por aspectos para além dos objetivos financeiros.

\section{CONSTRUÇÃO METODOLÓGICA}

Para analisar os fatores que levaram a empresa Guerra S.A. ao declínio organizacional, desenvolveu-se a presente investigação a partir de fontes jornalísticas. $O$ enfoque desta pesquisa é qualitativo, porque busca, conforme Martins (2006), "descrever, compreender e explicar comportamentos, discursos e situações" (p. 23), analisando principalmente argumentos e exposições em jornais e outras fontes de dados midiáticos. A pesquisa é de caráter interpretativista, no sentido de analisar os dados e dar um entendimento próprio, em detrimento de um cunho de mensuração de variáveis (Martins, 2006), e a abordagem é descritiva.

A empresa Guerra S.A., escolhida para este estudo, foi fundada em agosto de 1970 e sediada na Cidade de Caixas do Sul, no Estado do Rio Grande do Sul. A escolha da organização ocorreu por se tratar de uma organização que desde o início foi familiar e explorou um segmento de importância no âmbito econômico mundial. Outra motivação para a escolha foi a proximidade entre a empresa e seus funcionários, conforme verificado nos documentos analisados, o que é fundamental para a exploração da riqueza socioemocional, bem como a possibilidade de pesquisar a respeito de como uma organização de grande porte vivenciou o estágio de declínio, sendo uma das mais fortes em sua região e segmento.

Inicialmente se realizou uma primeira organização da documentação obtida, seguindo-se a lógica cronológica dos acontecimentos constantes dos documentos, também se observando, nesse preparo de materiais, ainda que de forma superficial, seu conteúdo (Laville \& Dionne, 1999). Para essa ordenação se realizou uma análise de conteúdo para esclarecer diferentes características encontradas e extrair significado aos achados. A análise de dados qualitativos é denominada, geralmente, análise de conteúdo (Moraes, 1999). Para o autor, esse tipo de estratégia é utilizado para descrever e interpretar o conteúdo de documentos e textos, sem distinção. $O$ conteúdo dos materiais coletados foi analisado e codificado, o que permitiu organizá-los a partir de temáticas, contextos e formatos. Para tanto, empregou-se a técnica de análise de conteúdo. Os constructos explorados estão descritos na Tabela 1: 
Tabela 1

Constructos explorados

\begin{tabular}{ll}
\hline Dimensão & Constructos \\
\hline Empresa familiar & $\begin{array}{l}\text { Propriedade: o controle é exercido pela família proprietária da empresa, a } \\
\text { qual possui seu controle ou a maior parte de seu capital (Leone, 2004). }\end{array}$ \\
\hline & $\begin{array}{l}\text { Estratégia: a ênfase mudará para capitalizar a eficiência nas fases de maturi- } \\
\text { dade e declínio; as últimas fases mostram a relativa proeminência de estra- } \\
\text { tégias como o corte de preços, e a publicidade, uma vez que estes se tornam } \\
\text { substitutos da inovação e oferecem maior eficiência (Miller \& Friesen, 1984). }\end{array}$ \\
\cline { 2 - 2 } & $\begin{array}{l}\text { Situação: retrata o ambiente externo (o ambiente aumentará em heteroge- } \\
\text { neidade e hostilidade à medida que as empresas expandirem sua gama de } \\
\text { produtos ou serviços em resposta a mercados mais maduros e saturados). }\end{array}$ \\
\cline { 2 - 2 } Declínio organizacional & $\begin{array}{l}\text { Estrutura: a sofisticação estrutural será reduzida na fase de declínio, quando } \\
\text { a estrutura tende a ser muito primitiva para permitir uma adaptação efetiva. }\end{array}$ \\
\cline { 2 - 2 } & $\begin{array}{l}\text { Estilo de tomada de decisão: caracterizada por um conservadorismo extremo, } \\
\text { há pouca inovação, aversão a assumir riscos, e uma relutância para comparti- } \\
\text { Ihar as inovações dos concorrentes. }\end{array}$ \\
\hline Riqueza socioemocional & Influência familiar no negócio (Gomez-Mejia et al., 20l4). \\
\hline
\end{tabular}

A primeira dimensão fundamenta-se na ideia de que uma empresa familiar foi o objeto da pesquisa. Apesar de a empresa Guerra S.A. ter transferido a propriedade para um grupo internacional, teve seu nascimento e expansão associados a esse tipo organização. A segunda dimensão refere-se aos constructos centrais do ciclo de vida organizacional (estratégia, situação, estrutura e estilo de tomada de decisão), analisados sob a ótica do declínio da empresa. A terceira e última dimensão justifica-se pelo interesse de explorar a influência familiar no negócio.

Conforme declarado na seção inicial desta investigação, a exploração dos constructos descritos no Quadro 1 proporciona entendimentos acerca de uma fase enfrentada por muitas organizações brasileiras, sobretudo em razão da crise econômica vivenciada nos últimos anos - o declínio organizacional. De forma complementar, o entendimento dos fatores que levaram uma empresa familiar ao declínio ganha eco quando se trata de uma organização que tem sua riqueza socioemocional abalada em decorrência da profissionalização da gestão e inserção de atores externos à empresa para ocupar papéis centrais na gestão do negócio.

\section{ANÁLISE E DISCUSSÃO DOS DADOS}

Os dados obtidos nesta pesquisa são analisados e discutidos em seções distintas, para o melhor entendimento e acompanhamento da evolução histórica da trajetória da Guerra S.A. 


\subsection{HISTÓRICO DA EMPRESA E PRIMEIRA SUCESSÃO}

A empresa Guerra S.A. Implementos Rodoviários foi uma das maiores fabricantes de implementos rodoviários da América Latina ("Notícias sobre," 2016). A partir da sua página do Facebook, a empresa salienta que a marca "PAZ na Estrada" se consolidou como referência de qualidade, tecnologia e inovação (Guerra Implementos Rodoviários S.A., 2015). Situada na Cidade de Caxias do Sul, no Rio Grande do Sul, a organização se encontra fechada e suas operações inativas. Fundada e constituída em agosto de 1970, a Guerra teve seu maior destaque a partir de 1972. A empresa obteve rápida ascensão, trabalhando com soluções para transporte rodoviário de cargas (Documento de Recuperação Judicial, 2017), concebida por integrantes de um grupo familiar, foi negociada e vendida em 2008 para um fundo internacional, a Axxon Group.

A história da empresa teve início com seu fundador Ângelo Francisco Guerra, que começou seu empreendimento na mesma época em que Raul Randon iniciava as atividades fazendo implementos rodoviários em Caxias do Sul e no mesmo bairro. Ambos tiveram altos e baixos e, por mais sombrio que possa parecer, foram vítimas, em momentos distintos, de incêndios que acabaram destruindo as instalações de suas empresas ("O fim," 2017). Mas, as semelhanças terminam aí, conforme a reportagem da Revista Modal. A morte prematura do fundador da Guerra S.A. antecipou a chegada da segunda geração ao comando da empresa, o que pode ter contribuído para a diferença na vida das duas organizações.

Ainda segundo a Modal (2017), houve decisões equivocadas decorrentes da sucessão prematura e após a negociação da empresa com o grupo internacional por quantia menor do que o valor considerado justo, a empresa acabou passando por inúmeras dificuldades de gestão, apesar do esforço do sucessor Marcos Guerra de dar continuidade às atividades da organização ("O fim," 2017).

A comemoração de 40 anos da empresa foi divulgada pelo site Caminhões e Carretas em 2010. Fazendo alusão à história de inovação e confiança da Guerra S.A., a reportagem apresentou dados da empresa, que contava com duas unidades industriais em Caxias do Sul, RS duas fábricas em Farroupilha, RS e uma em São Paulo, totalizando $208.535 \mathrm{~m}^{2}$ de área fabril e $50.440 \mathrm{~m}^{2}$ de área construída. A empresa tinha capacidade produtiva de fabricar 1.000 reboques e semirreboques de diferentes modelos, por mês, e contava com cerca de 2.000 funcionários na indústria e 1.500 colaboradores na Rede de Distribuidores ("Guerra comemora," 2010).

Ângelo Francisco Guerra fundou, em 1970, a Guerra S.A. com a finalidade de fabricar implementos rodoviários. Segundo Barbosa (2011), Deputado Estadual à época e segundo Secretário da Mesa Diretora da Assembleia, o dono consolidou a empresa e "Com o seu espírito empreendedor e conhecimento, projetou-a como uma das maiores fabricantes de 
semirreboques da América Latina, com a marca presente em 16 países e em aproximadamente 100 mil produtos em operação no mercado brasileiro" (p. 1).

Desde os nove anos de idade, Marcos Guerra começou a trabalhar na metalúrgica com o pai Ângelo, no contraturno escolar. Mesmo sem formação universitária, o sucessor fez diversos cursos na área empresarial e industrial, e era visto como um empresário com visão de negócio e espírito de liderança diferenciados ("Plano de," 2011). Ao longo dos anos em que esteve à frente da gestão da Guerra, Marcos construiu um império ancorado em valores e significados muito fortes, e foi extremamente habilidoso no sentido de despertar um sentimento de pertencimento muito forte nos funcionários com relação à organização. Dessa forma, ainda com pouco tempo de atuação, a Guerra S.A. transformou-se em uma grande potência, representando um espaço onde as pessoas (funcionários e aspirantes a funcionários) desejavam construir não apenas uma carreira, mas a extensão de suas vidas ("Plano de," 2011).

O fundador comandou a Guerra S.A. até a morte, nos anos 1980 ("O fim," 2017), mas durante muito tempo contou com o apoio do filho Marcos. Ainda jovem, Marcos Guerra começou a trabalhar na fabricação de implementos rodoviários, executando funções de soldador, guincheiro, motorista e pintor, para depois exercer o papel de administrador da Guerra S.A.

Conforme o Sindicato das Indústrias Metalúrgicas, Mecânicas e de Material Elétrico de Caxias do Sul (Simecs), em 2011 Marcos Guerra era Vice-presidente do Conselho de Administração da empresa, tendo recebido na circunstância o prêmio de Mérito Industrial do Rio Grande do Sul FIERGS/Ciergs. Ao receber tal condecoração, o herdeiro fez menção ao pai - reconheceu os ensinamentos recebidos do patriarca e relembrou a história da empresa que começou como uma pequena ferraria. O Mérito Industrial é uma premiação concedida pela Federação e pelo Centro das Indústrias do Rio Grande do Sul para distinguir industriais com marcante atuação na comunidade e no meio empresarial gaúcho. Os agraciados são indicados por sindicatos da indústria filiados à Federação das Indústrias do Estado do Rio Grande do Sul (FIERGS) e entidades associadas ao Centro das Indústrias do Rio Grande do Sul (Ciergs) e posteriormente escolhidos por uma Comissão Especial. Marcos Guerra foi indicado a receber o prêmio pelo Sindicato das Indústrias Metalúrgicas, Mecânicas e de Material Elétrico de Caxias do Sul (Simecs) ("Marcos Guerra," 2011).

\subsection{UMA "NOVA EMPRESA"}

Até 2008, Marcos Guerra esteve no comando da empresa da família. A partir da venda da Guerra S.A. ao Grupo Axxon, Marcos Guerra continuou no empreendimento familiar, entretanto como acionista minoritário, sendo detentor de $20 \%$ do capital da empresa 
("Notícias sobre," 2016). Entre os pontos evidenciados por Marcos, destaca-se a sugestão de criação de uma "Nova Empresa" na intenção de retomar as atividades iniciadas pelo pai. $O$ plano sugeriu a criação de uma Unidade de Produção Independente (UPI), que seria uma espécie de "Nova Guerra". Os credores seriam convidados a converter o valor da dívida por capital nessa nova estrutura, podendo resgatar o valor das ações a partir de 2024 . objetivo seria de ampliar as atividades da Guerra, que produziria implementos rodoviários e também artigos para outros tipos de indústrias. Marcos Guerra capitanearia, essa seria a nova estrutura, tendo uma participação de $5 \%$ e podendo chegar a até $30 \%$, dependendo do desempenho apresentado. A rede de distribuidores receberia cerca de $10 \%$ das ações e o restante seria composto pelos credores que optassem por converter seus créditos ("Notícias sobre," 2016).

Marcos fez a seguinte declaração à Gazeta Mercantil (citada por Inteligência em Gestão Logística [INTELOG], 2008): "Temos 37 anos de gestão, mas é uma gestão caseira. Precisamos olhar o futuro tendo uma visão mais consciente e dar um salto de qualidade em todos os processos" (p. 1). Com essa intenção, em 2008, foi concluída a negociação, em que o Grupo Axxon assumiu o controle acionário da empresa, que passou a se denominar Guerra S.A. Implementos Rodoviários (Associação Brasileira dos Distribuidores Guerra [Abradigue], 2008, p. 1). Nos anos seguintes, a família foi saindo do negócio, conforme o NTC (2012):

após a compra da Axxon em junho de 2008, a família Guerra manteve cargos de direção por um curto período na fase de transição, mas atualmente nenhum deles participa da gestão do grupo. Marcos, filho de Ângelo Guerra, foi o último a sair, após deixar a diretoria comercial em julho de 2010 (p. 1).

A composição familiar proposta na primeira dimensão de análise foi evidenciada por meio da disposição de informações nos meios de comunicação, indicativas de que o sucessor voltou a fazer parte do corpo gerencial da empresa, com participação de $20 \%$. Assim, a propriedade pode ser analisada como familiar, base pela qual o estudo foi consolidado.

A dimensão "situação da empresa" foi explorada a partir de reportagens publicadas em jornais. A Guerra S.A. possuía uma dívida de R\$ 212 milhões envolvendo financiamentos com bancos e débitos com fornecedores, o que motivou a empresa a solicitar recuperação judicial em 2015 ("Notícias sobre," 2016). Um dos prováveis motivos para a crise apresentada pela empresa foi a estagnação que a economia brasileira atravessou, o que culminou em demissões e desaceleração de investimentos em todo o território nacional. Uma razão apontada no Documento de Recuperação Judicial (2017) foi o "desaquecimento do mercado a partir de 2015" (p. 6). 


\subsection{CRISE FINANCEIRA E RECUPERAÇÃO JUDICIAL}

A estratégia - subdivisão da dimensão declínio organizacional-é evidenciada no Plano de Recuperação judicial apresentado pela Guerra. A Lei n. 11.101, de 9 de fevereiro de 2005, regula a recuperação judicial, a extrajudicial e a falência do empresário e da sociedade empresária. Conforme a Lei, o objetivo da recuperação judicial consiste em

viabilizar a superação da situação de crise econômico-financeira do devedor, a fim de permitir a manutenção da fonte produtora, do emprego dos trabalhadores e dos interesses dos credores, promovendo, assim, a preservação da empresa, sua função social e o estímulo à atividade econômica.

Além da crise financeira, outros fatores foram apontados pela empresa como contributivos para que a crise fosse desencadeada, como: redução do crédito no mercado a partir de 2015; retração do mercado de implementos rodoviários a partir de 2015; aumento da taxa de inadimplência; e redução da capacidade produtiva vis-à-vis à alavancagem da empresa. Todos estes fatores são relacionados como um conjunto de aspectos que levaram a empresa à falência (Documento de Recuperação Judicial, 2017, p. 6).

O Plano de Recuperação Judicial (2017) da Guerra S.A. Implementos Rodoviários, com foro na Cidade de Caxias do Sul, RS, foi estruturado conforme informações da Tabela 2:

Tabela 2

Organização do Documento de Recuperação Judicial

\begin{tabular}{ll}
\hline Preâmbulo & Apresentação da Empresa; Objetivos; Importância da Empresa \\
\hline Capítulo I & Definições e Interpretação \\
\hline Capítulo II & Reestruturação \\
\hline Capítulo III & Medidas Gerais de Recuperação da Guerra \\
\hline Capítulo IV & Pagamento dos Credores \\
\hline Capítulo V & Efeitos do PRJ \\
\hline Capítulo VI & Disposições Gerais \\
\hline
\end{tabular}

Houve uma tentativa de organizar a maneira pela qual a empresa seria restabelecida, seus credores pagos e funcionários devidamente realocados aos seus postos de trabalho para a continuidade do processo de produção e reestruturação geral da Companhia. Conforme registro no Documento de Recuperação Judicial (2017), a Guerra S.A. buscava transpor a crise econômica e financeira que vinha enfrentando, com a intenção de: 
(i) preservar a sua atividade empresarial, mantendo a atividade de suas plantas industriais para fins de comercialização de implementos rodoviários; (ii) manter a(s) fonte(s) de geração de riquezas, tributos e empregos; e (iii) estabelecer a forma de pagamento de seus Credores, sempre com vistas a atender aos seus melhores interesses.

A manifestação constante da empresa no referido documento demonstra seu interesse na manutenção das atividades, sugerindo, assim, que suas ações caminhavam na direção de promover a reestruturação da Organização, a partir das condições impostas pela legislação e pelo contexto ambiental. Apesar disso, a empresa fechou as portas e cessou as operações em maio de 2017.

$\mathrm{Na}$ ocasião da coleta de dados, o sítio institucional da empresa encontravase desativado ("fora do ar"), o que comprometeu a coleta de informações mais precisas e contundentes a respeito do que pode ter levado a empresa à falência. Outro meio de comunicação utilizado pela Guerra S.A. era a rede social Facebook, que possui sua última publicação datada de maio de 2017, com postagem referente a uma confraternização. Por esses motivos, o acesso a informações ocorreu por dados obtidos em outras fontes, que não a própria empresa, limitando a pesquisa a dados construídos por intermediários (notícias e entrevistas, por exemplo).

O Jornal Pioneiro de Caxias do Sul foi um dos principais meios de comunicação na divulgação concernente à Guerra S.A. Entre as reportagens analisadas, algumas foram selecionadas e resumidas na Figura 2 com o propósito de ilustrar as principais notícias concernentes à empresa estudada.

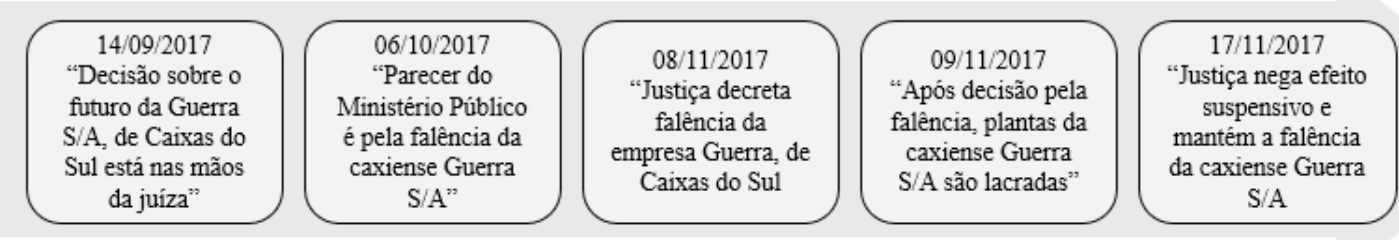

Figura 2. Resumo de reportagens.

Além da Figura 2, que busca demonstrar os principais fatos jornalísticos, elaborou-se a Tabela 3. Esta tem a intenção de esclarecer a evolução da Guerra S.A., desde sua fundação até o momento do declínio. 
Tabela 3

Evolução cronológica da vida da Guerra S.A.

\begin{tabular}{lll}
\hline Ano & Momento vivenciado & Revistas, jornais e sites \\
\hline 1970 & Fundação & $\begin{array}{l}\text { Documento de Recuperação Judicial } \\
(2017)\end{array}$ \\
1980 & Morte do fundador Ângelo Francisco Guerra & Modal (2017) \\
2008 & Marcos Guerra passa a deter apenas 20\% do capital & Pioneiro (2016) \\
2008 & Venda do capital para a empresa Axxon Group & Caminhões e Carretas (2010) \\
2015 & Início do processo de recuperação judicial & Modal (2017) \\
2017 & Decreto de falência & Modal (2017) \\
\hline
\end{tabular}

A Guerra S. A., uma das maiores fabricantes de implementos rodoviários da América Latina, começou a dar indícios de que foi afetada pela crise no setor metalomecânico em meados de 2015, com o pedido de recuperação judicial ingressado no Fórum de Caxias do Sul ("O drama," 2015). A decisão foi anunciada aos funcionários e tornou-se pública, destacandose a crise econômica que afetou grandes companhias do polo automotivo de Caxias do Sul, como Agrale, Randon e Marcopolo, e fez com essas empresas tomassem medidas como férias coletivas e flexibilização da jornada de trabalho, a fim de inibir demissões ("O drama," 2015).

Em matéria do Gl ("Empresa Guerra," 2017), foi destacada a crise do setor metalomecânico, influenciada, segundo o site, pela crise que assolou o País no ano de 2015. A reportagem abordou o pedido de recuperação judicial, destacou que a empresa possuía uma dívida de R\$210 milhões, e salientou que o faturamento mensal da Guerra S.A. caiu pela metade no ano de 2015, afetando seus 1,3 mil trabalhadores. Na ocasião, o advogado da empresa, Angelo Coelho ("Empresa Guerra," 2017), sinalizou que estavam tranquilos com relação à viabilidade da recuperação, inclusive afirmou o seguinte: "Não existe risco. Pagamos a folha, estamos produzindo, vamos ter que apresentar um plano, vamos ter que se reorganizar, é certo", referindo-se ao Plano de Recuperação aos credores, que foi organizado na intenção de evitar o fechamento da empresa. Outro representante da empresa foi ouvido pelo site, o consultor Antônio Augusto Vergani ("Empresa Guerra," 2017), que salientou: "Hoje a tendência é fazer exportações para suprir o mercado interno que está em crise" (p. 1), fazendo referência ao cenário da economia brasileira.

De acordo com o Jornal do Comércio ("Setor," 2017), a medida adotada pelas empresas de Caxias do Sul para enfrentar a crise no setor de veículos de transportes de cargas e passageiros foi a adoção de férias coletivas no final do ano de 2015. Segundo a reportagem, a Guerra S.A., mesmo em recuperação judicial, encontrava-se como segunda maior produtora de semirreboques do País. O diretor de operações, Roberto Vergani, declarou, na época, que a empresa já havia superado outras dificuldades, mas jamais havia enfrentado uma crise como a vivenciada em 2015, a qual reduziu a produção, o mercado e os postos de trabalho em massa e achatou os preços finais dos produtos ("Setor," 2017). 
O Jornal Pioneiro ("Notícias sobre," 2016) realizou reportagem em que descreve a situação a respeito do acionista da Guerra S.A., Marcos Guerra, detentor de 20\% do capital da empresa e diretor da MAM Participações, indicando que o empresário levou à Justiça uma série de questionamentos sobre a empresa e o processo de recuperação. Conforme a reportagem, havia divergências entre os sócios e Marcos Guerra. Este, na qualidade de membro da família originária e fundadora do negócio, contrapunha alguns argumentos do grupo controlador - o fundo internacional Axxon Group. $O$ empresário discordava dos rumos do processo de recuperação e da operação financeira que envolveria o imóvel da sede da empresa. Marcos Guerra justificou à reportagem que tal transação não estaria contemplada em um Plano de Recuperação viável. O advogado responsável pela recuperação judicial da Guerra S.A., Angelo Coelho, garantiu à coluna do Jornal Pioneiro que a integralização do pagamento dos salários de trabalhadores da produção seria realizada ("Notícias sobre," 2016).

Apesar de alguns fatos serem repercutidos na imprensa e jornais, foi a partir de maio de 2017 que a empresa efetivamente teve seu declínio oficializado e tornado público, fechando as portas e encerrando suas atividades produtivas. Conforme o Jornal Pioneiro ("Notícias sobre," 2016), até a votação do Plano de Recuperação judicial, a Guerra permaneceria de portas fechadas. Com salários e direitos atrasados, os colaboradores não trabalhavam desde 20 de maio, quando a companhia anunciou a interrupção das atividades.

\subsection{FALÊNCIA MOTIVADA PELO ENFRAQUECIMENTO DA RIQUEZA SOCIOEMOCIONAL}

Um fator relevante foi a perda dos vínculos estabelecidos na empresa familiar, que foram se perdendo com a concretização da venda da Guerra S.A. a um grupo estrangeiro que não se preocupou em manter as tradições vividas até então pela empresa ("Notícias sobre," 2016). O Jornal Pioneiro ("Notícias sobre," 2016) teve acesso a antigos colaboradores que relataram sobre as mudanças culturais acontecidas após a venda ao grupo internacional.

Em 2017, os sócios da Guerra S.A. defendiam diferentes caminhos para a recuperação da empresa, enquanto uma nova assembleia era marcada para julho, a fim de definir o caminho que seria seguido para a retomada das atividades e o pagamento das respectivas dívidas. Havia, conforme a reportagem destacou, uma batalha entre os acionistas majoritários da Axxon e o banco alemão DEG, que representavam $80 \%$ das ações da Tolstoi S.A., empresa controladora da Guerra S.A., e o representante da família Marcos Guerra, que possuía $20 \%$ das ações. As divergências giravam em torno de como o Plano de Recuperação seria colocado em prática, e com relação ao pagamento das dívidas, que seriam pagas por meio de obtenção de capital de giro com credores ("Notícias sobre," 2016). 
O advogado da Guerra S.A., Angelo Coelho, declarou que a empresa teria chances de se recuperar e conseguir os recursos necessários junto aos investidores, porém, os conflitos entre os acionistas poderiam atrapalhar tal intento. $\mathrm{Na}$ opinião do advogado, os recursos (jurídicos) e os conflitos travados entre os acionistas postergaram decisões importantes, impedindo que fossem oportunamente tomadas e, sobretudo, desgastando e prejudicando a forma de recuperação ("Notícias sobre," 2016).

A partir de setembro, a empresa tinha seu futuro nas mãos da juíza Claudia Brugger, que acenava para a possível definição da homologação, em até 30 dias, do Plano de Recuperação da Guerra S.A. Segundo o Jornal Pioneiro ("Notícias sobre," 2016), o processo tramitava de forma prioritária, mas não seriam preteridas as etapas legais concernentes ao processo. O advogado da parte majoritária, Angelo Coelho, foi pessoalmente à Cidade de Caxias do Sul no intuito de acelerar a tomada de decisão da juíza ("Notícias sobre," 2016).

O parecer do Ministério Público foi pela falência da caxiense Guerra S.A. em outubro de 2017. Para a promotora de Justiça Cível, Márcia Corso Ruaro, que cuidou do caso da empresa, os acionistas não demonstraram empenho no sentido da recuperação da empresa. Consonante à reportagem, o Ministério Público foi uma das vozes ouvidas no processo da Guerra. Ressaltou-se também que, caso a falência fosse decretada, o administrador judicial teria a responsabilidade de liquidar o patrimônio da empresa para pagar os credores. Em seu parecer, a promotora levou em conta que não haveria a possibilidade de recuperação da empresa, que paralisou as atividades em abril sem pagar os salários dos funcionários ("Notícias sobre," 2016).

O Jornal Pioneiro ("Notícias sobre," 2016) veiculou reportagem informando sobre o decreto, por parte da justiça, da falência da empresa Guerra. A decisão foi tomada pela juíza Maria Olivier, da $4^{a}$ Vara Cível de Caxias do Sul. Com a falência decretada, o administrador judicial tem a responsabilidade de liquidar o patrimônio da empresa para pagar os credores, dívidas que ultrapassam os $\mathrm{R} \$ 200$ milhões, além dos $\mathrm{R} \$ 14$ milhões devidos aos trabalhadores. De forma geral, a oficialização da falência era esperada, haja visto que, em outubro de 2017, - Ministério Público do Rio Grande do Sul (MP) havia encaminhado parecer reprovando o Plano de Recuperação da empresa e sinalizando a declaração de falência como o melhor desfecho para o processo ("Notícias sobre," 2016).

Após decisão pela falência e publicação da sentença por parte da juíza responsável pelo processo, as plantas da empresa Guerra S.A. foram lacradas. A juíza Maria Olivier considerou que a empresa já estava em um "estado falimentar" e sua situação era insustentável, pois o processo de recuperação tramitava desde 2015 e as atividades foram interrompidas em maio do ano de 2017 ("Notícias sobre," 2016).

O decreto da falência da Guerra também foi noticiado pelo Jornal do Comércio. A reportagem trouxe argumentos da Rádio Caxias, a qual expôs o problema enfrentado 
pela empresa no sentido de que ela não conseguiu solucionar problemas administrativos e financeiros, e diversas manifestações de funcionários que ocorreram nos últimos meses ("Setor," 2017).

O impasse econômico vivido pela Guerra S.A. Implementos Rodoviários desde julho de 2015, momento em que a empresa entrou com o pedido de recuperação judicial, chegou ao fim em novembro de 2017. Assim como noticiado por outras fontes, a Caminhões e Carretas-Portal de notícias sobre o transporte rodoviário no Brasil e no mundo-também transmitiu informações relacionadas à empresa. Segundo o site direcionado ao público-alvo da empresa, a saúde financeira da Guerra Implementos foi extremamente abalada nos últimos anos em decorrência da instabilidade econômica vivida no País, provocando forte queda no faturamento da empresa, que se agravou a partir do segundo semestre de 2014 ("Justiça decreta," 2017).

De acordo com o noticiado no Leouve, a Guerra Implementos Rodoviários teve seu decreto de falência oficializado em oito de novembro de 2017, fato que garantiu a possibilidade de liquidar seu patrimônio para efetuar o pagamento das dívidas contraídas ("Justiça decreta," 2017). Na mesma matéria, tem-se a transcrição de um trecho da decisão da juíza Maria Olivier, da $4^{a}$ Vara Cível de Caxias do Sul, que segue:

INDEFIRO o pedido das sociedades empresárias recuperandas GUERRA S.A. Implementos Rodoviários e TOLSTOI Investimentos S.A. de fls.9641-9677, datado de 10/07/2017, relativo à homologação judicial do plano de recuperação judicial da sociedade empresária recuperanda GUERRA S.A. Implementos Rodoviários, na forma do Artigo 58, § 1², da Lei n 11/101/2005;

Com fundamento no Artigo 73, inciso III, da Lei $n^{\circ} 11.101 / 2005$, porque rejeitados os planos de recuperação judicial na Assembleia Geral de Credores realizada em 05/07/2017, ata de fls.95449556, apresentados pelas sociedades empresárias recuperandas GUERRA S.A. Implementos Rodoviários, TOLSTOI Investimentos S.A. e MAM participações Eireli, bem como na forma do Artigo 94, da Lei $n^{\circ}$ 11.101/2005, DECRETO A FALÊNCIA da sociedade empresária GUERRA S.A. Implementos Rodoviários, CNPJ N 88.665.146/0001-05, e declaro aberta a falência, nesta data, ou seja, 08 de novembro de 2017, às 15 horas (p. 1).

Ademais dos termos técnicos/jurídicos do tratamento da questão, o que se pode interpelar a respeito do exposto é que o plano proposto pela empresa por meio de seus acionistas majoritários não obteve êxito, sendo marcado por protestos dos envolvidos diretamente com a empresa e que dependiam do empreendimento como sustento trabalhadores e ex-funcionários.

A Modal ("O fim," 2017)-Revista de Infraestrutura e Logística-noticiou o fim melancólico enfrentado pela empresa Guerra S.A. Segundo tal fonte, a falência é resultado da soma de equívocos e má gestão, em razão de uma condução na qual o Grupo Axxon 
se equivocou ao não considerar a cultura interna da empresa, desconsiderando aspectos importantes do negócio que ocupou posição de destaque entre os fabricantes de implementos rodoviários. Para Oli Soares Saldanha, que trabalhou 21 anos na empresa e, na ocasião, conselheiro do Sindicato dos Trabalhadores Metalúrgicos de Caxias do Sul, houve disputa pelo poder e uma má gestão do grupo internacional. Além disso, conforme a reportagem da Revista, aconteceram equívocos na escolha dos executivos, e as trocas frequentes (três mudanças em quatro anos) no alto comando influenciaram negativamente na empresa ("O fim," 2017).

O site Caminhões e Carretas ("Justiça decreta," 2017) anunciava mais um capítulo na recuperação da Guerra S.A. Havia a intenção de suspensão e reversão do decreto formalizado pela juíza responsável pelo processo. Tal intuito foi declarado por Angelo Coelho, advogado da empresa, em relato à jornalista da Rádio Gaúcha, Giane Guerra: "Ainda há condições de a Guerra retomar as atividades, equacionar dívidas e efetivamente se recuperar, o que será inviável se aguardando o julgamento do mérito". Porém, apesar da vontade explícita do advogado, a juíza Maria Olivier argumentou, no site Caminhões e Carretas ("Justiça decreta," 2017), que:

\footnotetext{
Não pairam dúvidas do estado falimentar em que se encontra a Guerra S.A. Implementos Rodoviários, pois, passados mais de dois anos, não logrou seguir na sua organização empresarial, tanto que, após um ano e meio do deferimento do pedido de recuperação judicial, paralisou suas atividades de produção, sendo claro o enfrentamento a credores, por insatisfação com os rumos tomados, tanto na efetiva recuperação, como nas questões do processo judicial (p. 1).
}

O Jornal Pioneiro ("Notícias sobre," 2016) retratava sobre a justiça, por meio da $5^{a}$ Câmara Cível do Tribunal de Justiça do Rio Grande do Sul (TJ-RS), ter negado o efeito suspensivo, mantendo a falência da caxiense Guerra S. A. Apesar de continuar com a tramitação, o recurso seria julgado somente em 2018 ("Notícias sobre," 2016).

Em uma seção de opinião do Jornal do Comércio em 2017, a empresária Bárbara Veit atribuiu ao seu posicionamento o seguinte título: "Mais uma indústria que perdeu a guerra" (Veit, 2017), fazendo alusão - e um trocadilho com a batalha pela qual a empresa Guerra S.A. passou - ao cenário de instabilidade econômica em que a empresa se encontrava no momento de todo o processo de falência, situação que se arrastou desde 2015, com o início da recuperação judicial da Guerra S. A. e que não se transformou em superação da empresa. Ela também traz dados da Associação Nacional dos Fabricantes de Implementos Rodoviários (ANFIR), em que são disponibilizadas informações a respeito da contração $e$ da queda no mercado de implementos rodoviários, de 159.870 implementos em 2014, para 88.318 em 2015 , uma queda de $44,76 \%$ no setor abarcado pela empresa. A empresária atribui 
à grandiosidade da empresa como um dos fatores para a dificuldade em sair da crise instalada, e conclui:

O que é triste é que vivemos em um país de economia montanha-russa, de momentos de cumes e sopés. Às vezes, parece que não somos empresários e administradores, mas sim malabaristas e equilibristas, tentando, a cada nova adversidade, equilibrar mais uma bola (Veit, 2017).

De acordo com o Jornal Pioneiro (Soares, 2018), no ano de 2018 aconteceu o leilão dos bens, com previsão de arrecadação de R $\$ 2$ milhões, e o bloqueio feito por manifestantes em protesto por dívidas trabalhistas da empresa caxiense. Ativos como automóveis, caminhões, implementos rodoviários e empilhadeiras foram negociados (Soares, 2018). O site Caminhões e Carretas ("Guerra Implementos," 2018) veiculou reportagem semelhante, informando que a empresa aguardava a venda de seus bens e que, segundo o administrador judicial Cristiano Fran, o processo demorou mais do que o esperado porque inicialmente não foram encontrados cinco veículos.

Por fim, o Jornal Pioneiro (Soares, 2018) retratou a autorização, pela $4^{a}$ Vara Cível, para a venda pública dos bens da massa falida da Guerra S.A., com suposta realização em maio, selando o fim efetivo das operações da empresa. Apesar dos esforços declarados no Plano de Recuperação, as ações empreendidas não tiveram êxito na reestruturação. A partir desse momento, a empresa já estava inserida em um contexto de decadência; sua estrutura encontrava-se no ponto de declínio e já não havia mais meios para alavancar seus negócios, ou seja, a composição da empresa ruiu e seus componentes não se mostravam mais dispostos a se empenhar com a reestruturação (Soares, 2018).

O estilo de tomada de decisão pode ser configurado por decisões mais conservadoras, entretanto, no caso da Guerra S.A. o que foi observado nas reportagens é que não houve muitas decisões efetivamente tomadas em prol da reabertura e do funcionamento da empresa. Apesar de ter tomado a decisão de elaborar um Plano de Recuperação e de seguir todo o protocolo para não encerrar definitivamente suas atividades, a empresa não colocou, de fato, as propostas em prática. Os problemas informacionais e de decisão podem ter culminado com o efetivo declínio da Guerra S.A.

Os achados reforçam o quão importantes são os elementos da riqueza socioemocional para que uma empresa familiar possa ser gerenciada com sucesso. A profissionalização da gestão de uma organização e sua venda para um grupo estrangeiro devem ser realizadas com muita cautela quando se trata de uma empresa que conservou base familiar por longo período de tempo. Isso porque os membros da família e também os colaboradores que durante muito tempo atuaram na Guerra S.A. criaram vínculos sociais que não podem ser desprezados para a boa fluidez das operações. 
Além das reportagens analisadas neste artigo, há vasta gama de informações disponíveis no site do Sindicato dos Metalúrgicos de Caxias do Sul, um portal dos trabalhadores de Caxias do Sul e região. Porém, em razão da delimitação deste artigo pela seletividade de um viés mais geral sobre os acontecimentos da empresa, optou-se por privilegiar as reportagens apresentadas, em detrimento daquelas que, apesar de um viés alternativo, também poderão servir, em uma futura pesquisa, para mais entendimentos do declínio da Guerra S.A.

\section{CONSIDERAÇÕES FINAIS}

Este estudo teve como objetivo analisar os fatores que levaram a empresa Guerra S.A. ao declínio, por meio da análise de conteúdo das reportagens de jornais e outras mídias virtuais. Assim, buscou-se reunir informações relativas à empresa no período de 2015 a 2018.

A fase de declínio da empresa teve início em 2015 e culminou com o encerramento das atividades em 2017. Entre os aspectos que consolidaram o declínio da Guerra S.A. está a grave crise financeira vivenciada no País no ano de 2015, porém agravada por alguns fatores, como: morte do fundador da empresa; venda ao Grupo Axxon; decisões organizacionais divergentes entre acionista da família e detentor internacional foram verificadas como cruciais para o desfecho de não retomar as atividades fabris da empresa. Não existe consenso, baseando-se em dados secundários, sobre o que aconteceu realmente para a empresa chegar ao declínio em um espaço relativamente curto de tempo. $O$ declínio e, consequentemente, a falência e o encerramento das atividades da Guerra S.A. deveram-se muito pelo fato de os tomadores de decisão não atuarem de forma eficaz e unificada na resolução dos problemas enfrentados pela empresa. Não há como uma empresa ultrapassar crises sem nenhum estremecimento (como a vivenciada pela empresa em 2015), mas é possível que, com esforço e dedicação, os abalos sofridos sejam amenizados, sendo até mesmo concebível a pronta recuperação de uma empresa que passou por um procedimento judicial de recuperação.

A empresa familiar, por vezes, tem um perfil mais imediatista, o que vai de encontro ao planejamento organizacional (Gonçalves, 2000). Quando o planejamento estratégico é pretendido na empresa familiar, devem-se observar as peculiaridades desse tipo de empreendimento, em razão do fato da existência de questões familiares que precisam ser incorporadas (Ward, 1988). Na Guerra S.A. houve a intenção da superação das dificuldades da empresa, a partir do Plano de Recuperação proposto, entretanto, não foi obtido o sucesso almejado, o que acarretou a extinção da organização. Assim, os achados confirmam que - afastamento da família da gestão da Guerra S.A. abalou a riqueza socioemocional da organização, comprometendo que o conhecimento acerca de sua história e sua cultura fosse articulado com habilidades e competências necessárias à gestão e possível retomada das 
atividades. Em síntese, as habilidades e o conhecimento que a família tem acerca do negócio e que são fundamentais para sua manutenção (Mazzola, Marchisio, \& Astrachan, 2008) foram comprometidos. Tais elementos se mostravam essenciais enquanto a Guerra S.A. ainda estava sustentada pela base familiar e, ao ser negociada ao Grupo Axxon, a Guerra S.A. teve sua riqueza socioemocional desprezada.

A pesquisa restringiu-se à análise de materiais de jornais e do Plano de Recuperação da empresa. Dessa forma, os achados estão delimitados por essa estratégica de reunião de dados. O declínio organizacional, especialmente em uma organização de grande porte, é um processo amplo e sua compreensão demanda maior aproximação com a organização, o que representa um próximo passo à pesquisa. Uma expansão dos resultados provável poderá ser obtida com entrevistas aos ex-funcionários da empresa e por meio de contato com sindicatos e entidades de classe envolvidas com o setor, métodos que exigem aprofundamento e tempo para análise.

\section{REFERÊNCIAS}

Associação Brasileira dos Distribuidores Guerra. (2008). Recuperado de https://www. abradigue.com.br/abradiguel

Barbosa, A. Alceu registra feito de empresa caxiense. (2011). Recuperado de https://alceubarbosavelho.wordpress.com/page/107/

Berrone, P., Cruz, C., \& Gomez-Mejia, L. R. (2012). Socioemotional wealth in family firms: Theoretical dimensions, assessment approaches, and agenda for future research. Family Business Review, 25(3), 258-279.

Documento de Recuperação Judicial. (2017). Recuperado de mazzardoecoelho.com.br

Empresa Guerra S.A. entra com pedido de recuperação judicial no RS. (2017). Gl. Caderno de Economia. Recuperado de http://gl.globo.com/rs/rio-grande-do-sul/noticia/2015/07/empresa-guerra-s-entra-com-pedido-de-recuperacao-judicial-no-rs.html

Frezatti, F., Bido, D. S., Mucci, D. M., \& Beck, F. (2017). Estágios do ciclo de vida e perfil de empresas familiares brasileiras. RAE-Revista de Administração de Empresas, 57(6), 601-619.

Giovannoni, E., Maraghini, M. P., \& Riccaboni, A. (2011). Transmitting knowledge across generations: The role of management accounting practices. Family Business Review, 24(2), $126-$ 150. 
Gomez-Mejia, L., Cruz, C., \& Imperatore, C. (2014). Financial reporting and the protection of socioemotional wealth in family-controlled firms. European Accounting Review, 23(3), 387 402.

Gonçalves, J. S. R. C. (2000). As empresas familiares no Brasil. Revista de Administração de empresas, $40(1), 7-12$.

Guerra comera 40 Anos: Uma história marcada pela inovação e confiança. (2010). Caminhões e Carretas. Recuperado de https://www.caminhoes-e-carretas.com/2010/08/guerra-comera-40-anos-uma-historia.html

Guerra de Caxias do Sul prepara mudanças no controle societário. (2008). Inteligência em Gestão Logística. Recuperado de www.intelog.net>Início>News Log>Notícias>Empresas

Guerra Implementos Rodoviários S.A. (2015). Facebook. Recuperado de https://pt-br.facebook. com/pages/Guerra-SA-Implementos-Rodovi\%C3\%Alrios/105458536224454

Guerra Implementos terá bens leiloados por 2 milhões após falência. (2018, Fevereiro). Caminhões e Carretas. Recuperado de https://www.caminhoes-e-carretas.com/2018/02/guerra-implementos-tera-bens-leiloados.html

Helsen, Z., Lybaert, N., Steijvers, T., Orens, R., \& Dekker, J. (2017). Management control systems in family firms: A review of the literature and directions for the future. Journal of Economic Surveys, 31(2), 410-435.

Jupetipe, F. K. N. (2017). Utilidade da informação contábil para eficiência dos processos de falência e de recuperação empresarial (Tese de doutorado). Universidade de São Paulo, São Paulo.

Justiça decreta falência da empresa Guerra. (2017). Leouve. Recuperado de https://leouve. com.br/justica-decreta-falencia-da-empresa-guerra-s/

Justiça decreta falência da Guerra Implementos Rodoviários. (2017). Caminhões e Carretas. Recuperado de https://www.caminhoes-e-carretas.com/2017/11/justica-decreta-falencia-da-guerra.html

Kalm, M., \& Gomez-Mejia, L. R. (2016). Socioemotional wealth preservation in family firms. Revista de Administração, 51(4), 409-411.

Laville, C., \& Dionne, J. (1999). A construção do saber: Manual de metodologia da pesquisa em ciências humanas. Artmed: UFMG. 
Lei 11.101, 2005.

Leone, N. M. D. C. P. (2004). O processo sucessório em empresas familiares: $O$ exemplo dos comerciantes e o processo no Saara. Organizações \& Sociedade, 11(29), 149-172.

Marcos Guerra recebe Prêmio Mérito Industrial da FIERGS/CIERGS. (2011). Logweb. Recuperado de http://www.logweb.com.br/marcos-guerra-recebe-premio-merito-industrial-da-fiergsciergs/

Martínez-Romero, M. J., \& Rojo-Ramírez, A. A. (2016). SEW: Looking for a definition and controversial issues. European Journal of Family Business, 6(1), 1-9.

Martins, G. D. A. (2006). Estudo de caso: Uma estratégia de pesquisa. São Paulo: Atlas.

Mazzola, P., Marchisio, G., \& Astrachan, J. (2008). Strategic planning in family business: A powerful developmental tool for the next generation. Family Business Review, 21(3), 239 258.

Miller, D., \& Breton-Miller, I. (2014). Deconstructing socioemotional wealth. Entrepreneurship Theory and Practice, 38(4), 713-720.

Miller, D. \& Friesen, P. (1984). A longitudinal study of the corporate life cycle. Management Science, 30(10), 1161-1183.

Modal, R. (2017). O fim melancólico da Guerra Implementos Rodoviários, de Caxias do Sul. Recuperado de http://revistamodal.com.br/o-fim-melancolico-da-guerra-implementos-rodoviarios-de-caxias-do-sul/

Moraes, R. (1999). Análise de conteúdo. Revista Educação, 22(37), 7-32.

Mucci, D. M. (2018). Management control mechanisms and stewardship in family firms: An analysis of antecedents and consequences (Tese de doutorado). Universidade de São Paulo, São Paulo.

Necyk, G. A., \& Frezatti, F. (2010). A Contabilidade Gerencial: Uma perspectiva de ciclo de vida de seu desenvolvimento nas organizações. Organizações \& Sociedade, 17(55).

Notícias sobre Guerra SA. (2016). Jornal Pioneiro. Recuperado de http://pioneiro.clicrbs.com. $\mathrm{br} / \mathrm{rs} /$ ultimas-noticias/tag/guerra-sa/ 
NTC, P. (2012). Recuperado de https://www.portalntc.org.br/publicacoes/blog/noticias/industria-de-transportes/trimestre-marca-recuperacao-no-setor-de-implementos-rodoviarios

O drama vivido pelos funcionários da empresa caxiense Guerra S.A. (2017). Jornal Zero Hora. Recuperado de https://gauchazh.clicrbs.com.br/geral/noticia/2017/09/o-drama-vivido-pelos-funcionarios-da-empresa-caxiense-guerra-sa-9900964.html

Plano de recuperação judicial da Guerra S.A. pode ser homologado pela Justiça. (2011). Rádio Caxias. Recuperado de https://www.radiocaxias.com.br/portal/noticias/plano-de-recuperacao-judicial-da-guerra-sa-pode-ser-homologado-pela-justica-78148

Prencipe, A., Bar-Yosef, S., \& Dekker, H. C. (2014). Accounting research in family firms: Theoretical and empirical challenges. European Accounting Review, 23(3), 361-385.

Price Waterhouse e Coopers Brasil. (2016). Pesquisa Global sobre Empresas Familiares.

Ribeiro, J., Filho, Lopes, J., \& Pederneiras, M. (2009). Estudando teoria da contabilidade. São Paulo: Atlas.

Sanchez-Famoso, V., Maseda, A., \& Iturralde, T. (2013). Relationship between family and non-family social capital: The case of Spanish family firms. Revista Europea de Dirección y Economía de la Empresa, 22(4), 177-185.

Santos, R. P., \& Barbosa, R. V. N. (2011). Contabilidade Gerencial, ciclo de vida e poder: À luz da biopolítica de Foucault. Gestão Contemporânea, (8).

Serra, F. A. R., Pinto, R., Guerrazzi, L., \& Ferreira, M. P. (2017). Organizational decline research review: Challenges and issues for a future research agenda. BAR-Brazilian Administration Review, 14(2).

Setor metalmecânico para 30 dias na Serra. (2017). Jornal do Comércio. Recuperado de http:// jcrs.uol.com.br

Silva, A., Jr., \& Muniz, R. M. (2003). Poder e sucessão: ascensão, declínio e falência de uma gestão familiar em uma empresa capixaba. Organizações \& Sociedade, 10(26).

Soares, F. (2018). O futuro da Guerra SA. Pioneiro. Recuperado de http://especiais-pio.clicrbs.com.br/maisserra/18/central.html

Stankiewicz, J. (2016). Socioemotional wealth and the performance of family firms: The role of identification and transgenerational control (Doctoral dissertation). Universität St. Gallen, Gallen, Switzerland. 
Três, D. L. (2010). Declínio e turnaround: Um estudo de caso em uma empresa familiar (Dissertação de mestrado). Universidade Federal de Santa Catarina, Florianópolis.

Valente, N. T. Z. (2014). Qualidade da informação contábil na perspectiva da ciência da informação (Tese de Doutorado). Universidade de São Paulo, São Paulo.

Veit, B. (2017). Mais uma indústria que perdeu a guerra. Jornal do Comércio. Recuperado de https://www.jornaldocomercio.com/_conteudo/2017/12/opiniao/603264-mais-uma-industria-que-perdeu-a-guerra.html

Ward, J. L. (1988). The special role of strategic planning for family businesses. Family Business Review, 1(2), 105-117.

\section{Como citar este artigo:}

\section{ABNT}

BUCHWEITZ, Michele Josiane Rutz et al. A riqueza socioemocional e o declínio em uma empresa familiar: um estudo da Guerra S.A. RACE, Revista de Administração, Contabilidade e Economia, Joaçaba: Ed. Unoesc, v. 18, n. 2, p. 231-258, maio/ago. 2019. Disponível em: http://editora.unoesc.edu.br/index.php/race. Acesso em: dia/mês/ano.

\section{APA}

Buchweitz, M. J. R., Cruz, A. P. C. da, Barbosa, M. A. G., \& Pereira, T. A. (2019). A riqueza socioemocional e o declínio em uma empresa familiar: Um estudo da Guerra S.A. RACE, Revista de Administração, Contabilidade e Economia, 18(2), 231-258. Recuperado de http:// editora.unoesc.edu.br/index.php/race 